\title{
Contributions towards the knowledge of Favolaschia (Mycenaceae, Agaricomycetes) from Brazil
}

\author{
Magnago $\mathrm{AC}^{1}$, Trierveiler-Pereira $\mathrm{L}^{2}$ and Neves $\mathrm{MA}^{1}$ \\ ${ }^{1}$ Programa de Pós-Graduação em Biologia de Fungos, Algas e Plantas, Departamento de Botânica, Universidade \\ Federal de Santa Catarina, Florianópolis, Santa Catarina, Brazil. Altielys@gmail.com \\ ${ }^{2}$ Programa de Pós-Graduação em Botânica, Departamento de Botânica, Universidade Federal do Rio Grande do Sul, \\ Porto Alegre, Rio Grande do Sul, Brazil.
}

Magnago AC, Trierveiler-Pereira L, Neves MA 2013 - Contributions towards the knowledge of Favolaschia (Mycenaceae, Agaricomycetes) from Brazil. Mycosphere 4(6), 1071-1078, Doi 10.5943/mycosphere/4/6/5

\begin{abstract}
Favolaschia is a representative genus in the Brazilian Atlantic Forest where four species have been recently identified: Favolaschia cinnabarina, $F$. dealbata, $F$. rubra and $F$. selloana. Favolaschia dealbata is a new record for Brazil and F. selloana is new for Southeastern Brazil. Color images of the basidiomata, complete descriptions and illustrations of the four species are presented.
\end{abstract}

Key words - Agaricales - fungal taxonomy - neotropical mycota

\section{Introduction}

Favolaschia (Pat.) Pat. is a genus of usually small, mushroom-like basidiomycetes that occur worldwide, especially in the tropics. Members of the genus are often characterized by their poroid hymenophore, amyloid spores, frequent presence of gloeocystidia and acanthocystida and a trama that is usually gelatinous (Gillen et al. 2012). Favolaschia comprises approximately 50 species (Singer 1974, Parmasto 1999, Kirk et al. 2008) and about 20 of these have been reported for Brazil (Gillen et al. 2012). The first records of the genus in Brazil are from the nineteenth century (e.g. Spegazzini 1889, Bresadola 1896, Hennings 1897). More recent records include the description of a new species, F. luteoaurantiaca Capelari, Karstedt \& J.S. Oliveira (Singer 1974, Singer \& Fidalgo 1965, Capelari et al. 2013).

Although Favolaschia species are very common in the Brazilian Atlantic forests, few species have been reported from the state of Santa Catarina, in Southern Brazil: F agaricina (Mont.) Kuntze, F. cinnabarina (Berk. \& M.A. Curtis) Pat., F. flava (Bres.) Kuntze, F. moelleri (Bres.) Singer and F. rubra (Bres.) Kuntze (Bresadola 1896, Capelari et al. 2013). This article presents descriptions and illustrations of four Favolaschia species recently identified from Southeastern (Espírito Santo State) and Southern Brazil (Santa Catarina State). Favolaschia dealbata is a new record for Brazil and F. selloana is a new record for Southeastern Brazil and the first record of the genus for the state of Espírito Santo (Vinha 1988).

\section{Materials \& Methods}

Field expeditions were carried out in Santa Catarina (Southern Brazil) at Vargem do Braço, a 
small area in the municipality of Santo Amaro da Imperatriz, and in Reserva Biológica Volta Velha, in Itapoá. In the State of Espírito Santo (Southeastern Brazil) collections were made in Reserva Biológica Augusto Ruschi, Santa Teresa. The predominant vegetation type in these areas is Atlantic Forest (Dense Ombrophilous Forest) and the climate is subtropical to tropical with high annual rainfall $(1800 \mathrm{~mm})$. Altitudes range from 350 to $750 \mathrm{~m}$ a.s.l., and the mean annual temperature varies between $20^{\circ} \mathrm{C}$ and $24^{\circ} \mathrm{C}$ in January (Summer) and $12^{\circ} \mathrm{C}$ and $16^{\circ} \mathrm{C}$ in July (Winter).

Basidiomata were slowly dried at a low temperature (about $40^{\circ} \mathrm{C}$ ), on an electric dryer (Total Chef TCFD-05 Deluxe), and later analyzed (macro and microscopically) according to Singer (1974). Macroscopic features are described based on dried specimens. Colors were based on Kornerup \& Wanscher (1978). Microscopic observations were made with KOH, congo red, cresyl blue or Melzer's reagent. Vouchers are deposited at FLOR (Thiers 2013).

\section{Results and Discussion}

Favolaschia cinnabarina (Berk. \& M.A. Curtis) Pat., Essai Tax. Hyménomyc. (Lons-le-Saunier): 141, 1900.

Figs $1 \mathrm{~A}-2$

Basidiomata gregarious; pileus $0.4-0.8 \mathrm{~mm}$ in diam., semiglobose, reddish orange (7A8) to orange $(6 \mathrm{~A} 8,6 \mathrm{~A} 7)$, glabrous to slightly pruinose, pruina lighter than pileus color. Hymenophore poroid, ca. 3-4 pores per mm, irregular; pore edges concolorous with surface, dissepiments thick. Stipe absent to poorly developed, laterally attached.

Basidiospores 8-10 × 5-8 $\mu \mathrm{m}(\mathrm{Q}=1.4)$, broadly ellipsoid to ovoid, smooth, hyaline, amyloid. Basidia $26 \times 8 \mu \mathrm{m}$, clavate, thin walled, hyaline; 2-spored, sterigmata $3 \mu \mathrm{m}$ long. Hymenial gloeocystidia 30-34 $\times 5-8 \mu \mathrm{m}$, clavate, scattered, with golden yellow oily contents, inamyloid. Pileipellis composed of acanthocystida and gloeocystidia; gloeocystidia 31-55 $\times 8-11 \mu \mathrm{m}$, clavate, with golden yellow oily contents, inamyloid; acanthocyst spiny on the upper two third, spines 1-2 $\mu \mathrm{m}$ long, clavate to pyriform, 26-31 ×7-9 $\mu \mathrm{m}$, hyaline. Trama of the pileus interwoven, $2-4 \mu \mathrm{m}$ broad, hyaline, inamyloid, immersed in gelatinized matrix, clamp connections present.

Habitat - growing on dead herbaceous twigs.

Distribution - Bolivia, Brazil, British Guyana, Colombia, Cuba, Ecuador, Panama, Venezuela (Singer 1974, Gillen et al. 2012). In Brazil, the species is cited for the states of Paraná (Meijer 2001, 2006, 2008), Rondônia (Capelari and Maziero 1988), Santa Catarina (Capelari et al. 2013) and São Paulo (Singer 1974; Pegler 1997, Capelari et al. 2013).

Material examined - Brazil, Santa Catarina, Itapoá, Reserva Biológica Volta Velha, 18 November 2012, Urrea-Valencia, S. 204 (FLOR 49850).

Remarks - Favolaschia cinnabarina is recognized by the following: a vibrant pigmented, reddish-orange basidiomata; stipe absent to poorly developed; pilleipelis with numerous gloeocystidia and empty acanthocystida; hymenial gloeocystidia with golden yellow, oily content; basidiospores broadly ellipsoid, 8-10 $\times 5-8 \mu \mathrm{m}$; and gelatinized trama. Following Singer (1974), $F$. cinnabarina fits into section Favolaschia subsection Auriscalpium, a group distinguished by its taxa with brightly pigmented basidiomata, conspicuous gloeocystidia and distinct acanthocystidia.

Favolaschia gaillardia is very similar to $F$. cinnabarina due to its reddish basidiomata; however, the former species usually has larger basidiomata $(2.8-5.0 \mathrm{~mm}$ in diam.) and its basidiospores are broadly ellipsoid to ovoid (Singer 1974, Pegler 1997).

Favolaschia dealbata Singer, Mycologia 47(5): 763, 1955.

Figs 1B-3

Basidiomata gregarious, usually not confluent; pileus $0.6-1.6 \mathrm{~mm}$ in diam., semiglobose to fan-shaped, deep orange (6A8) to orange $(6 \mathrm{~A} 6,6 \mathrm{~A} 7)$, glabrous to slightly pruinose, pruina concolorous with the surface; tessellate by transparence (corresponding to the pore dissepiments). Hymenophore poroid, ca. 5-6 pores per $\mathrm{mm}$, pores $0.05-0.25 \mathrm{~mm}$ in diam., irregular to favoloid in shape, some round near the margin; pore edges grayish orange (5B5). Stipe $0.8-1.8 \mathrm{~mm}$ in lenght; deep orange (5A8) to light orange (5A5), glabrous to slightly pruinose, laterally attached. 

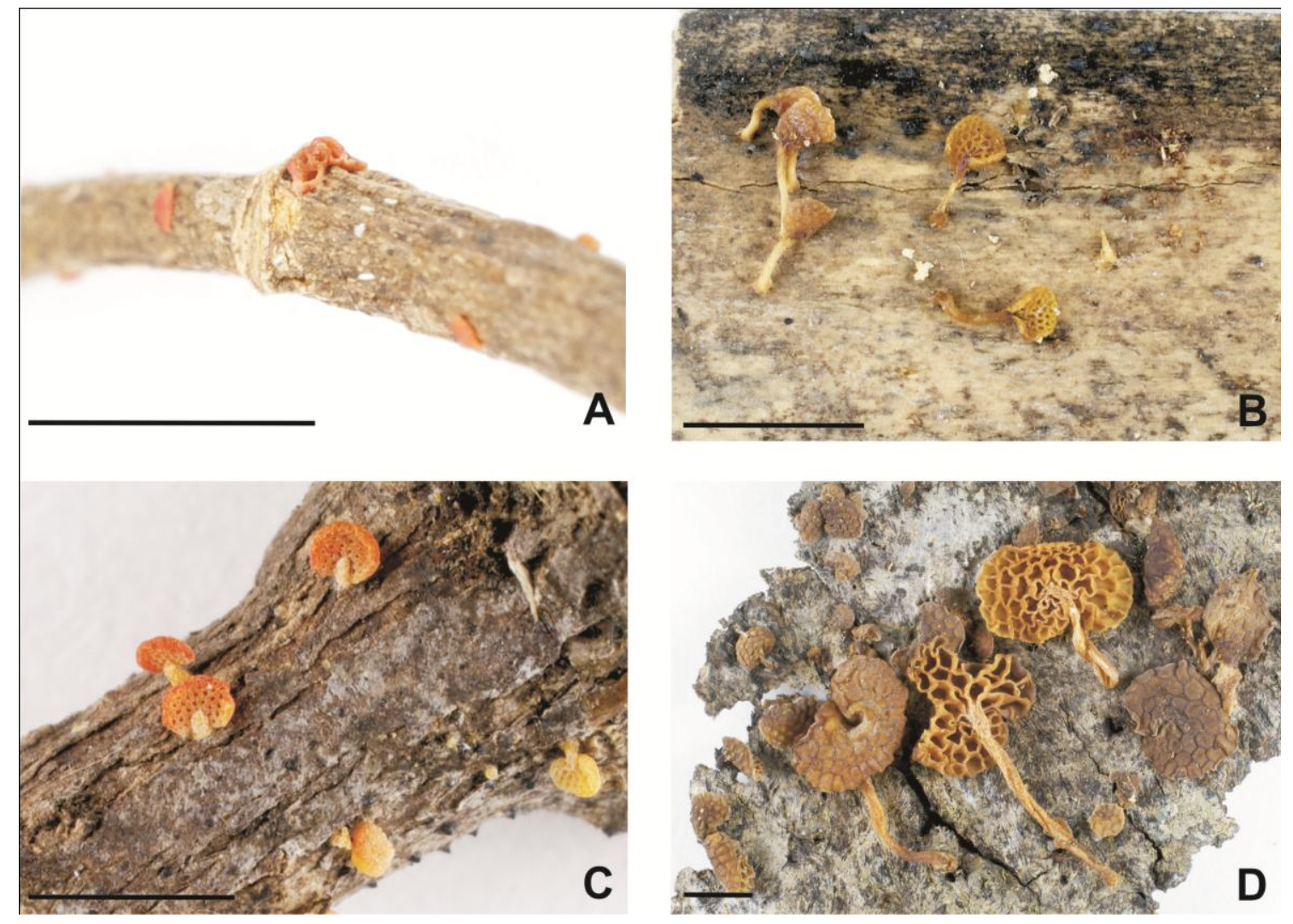

Fig. 1 - Dried basidiomata: A F. cinnabarina, B F. dealbata, C F. rubra, D F. selloana (Scale: 3 $\mathrm{mm})$.

Basidiospores 8-9.5 × 5-6 $\mu \mathrm{m}(\mathrm{Q}=1.6)$, broadly ellipsoid to subglobose, smooth, thin-walled, usually with a central oil drop, amyloid. Basidia cylindric to clavate, 4-spored. Hymenial gloeocystidia not abundant, cylindrical to broadly cylindrical, 19-28 $\times 5-7 \mu \mathrm{m}$, smooth, with golden yellow to orange oily content. Pileipellis composed of acanthocystida and gloeocystidia; acanthocystida clavate to broadly clavate, $20-28 \times 11-24 \mu \mathrm{m}$, densely spinulose over the upper half, hyaline to light yellow; gloeocystidia, clavate to broadly clavate, $23-39 \times 12-18 \mu \mathrm{m}$, smooth, with gold-yellow to orange oily content. Trama slightly gelatinous, hyphae irregularly arranged in pileus trama, thin-walled, clamp connections absent.

Habitat - growing on dead culms of native bamboo (Chusquea sp.).

Distribution - Panamá (Singer 1955), Ecuador (Gillen et al. 2012) and Brazil (present study).

Material examined - Brazil, Santa Catarina, Santo Amaro da Imperatriz, Vargem do Braço, 12 November 2006, L. Trierveiler-Pereira s/n (FLOR 32187).

Remarks - Favolaschia dealbata is characterized by the following: orange, non-gelatinous basidiomata; laterally attached stipe; pileipellis composed of acanthocystida and gloeocystidia; 4spored basidia; basidiospores broadly ellipsoid, 8-9.5 × 5-6 $\mu \mathrm{m}$; and hyphae without clamp connections (Gillen et al. 2012). In tropical America, the species has been found at high altitudes (ca 2000-2800 $\mathrm{m}$ a.s.1.), but the Brazilian specimen was found at a lower altitude (ca. 350-600 m a.s.l.) in a subtropical forest.

The substratum is also an important feature used to identify this species because it has always been collected on bamboo (Singer 1955, Gillen et al. 2012). According to Singer (1974), most species of Favoslachia are specific to a particular substratum, although some species might be found on different substrata (e.g., F. calocera). Another South American species known to occur on dead bamboo is F. aurantiaca Singer (reported from Argentina, Bolivia, Ecuador and Panama); however, this species has white to brown, gelatinous basidiomata (Gillen et al. 2012).

Favolascia dealbata is phylogenetically related to $F$. calocera R. Heim, a common paleotropical species that also has orange basidiomata and gloeocystidia in the pileipellis (Vizzini 
et al. 2009, Gillen et al. 2012). Both species can be easily separated because $F$. calocera has 2spored basidia, larger basidiospores (9-13.5 $\mu \mathrm{m}$ in length), and does not grow specifically on bamboo.

Favolaschia luteoaurantiaca Capelari, Karstedt \& J.S. Oliveira, recently described from Brazil, also shares similar macroscopic features with $F$. dealbata, but the first was found growing on dicotyledon shrubs and the basidiomata color ranges from orange to yellow. Moreover, basidiospores of $F$. luteoaurantiaca are slightly smaller (7.5-8.5 $\mu \mathrm{m}$ long) (Capelari et al. 2013).

Favolaschia rubra (Bres.) Kuntze, Revis. gen. pl. (Leipzig) 3(2): 476, 1955.

Figs $1 \mathrm{C}-4$

Basidiomata gregarious; pileus $0.3-1.0 \mathrm{~mm}$ in diam., semiglobose, brownish orange $(6 \mathrm{C} 8)$ to orange $(6 \mathrm{~A} 7,6 \mathrm{~A} 8)$, slightly pruinose, pruina whitish to yellowish. Hymenophore poroid, ca. 7-8 pores per mm; pore irregular to round, edges light orange (6A5), dissepiments thick. Stipe 0.3-0.6 $\mathrm{mm}$ in lenght; light orange (6A5, 6A6), slightly pruinose, laterally attached.

Basidiospores 6-8 $\times$ 5-6 $\mu \mathrm{m}(\mathrm{Q}=1.2)$, ellipsoid, hyaline, smooth, thin-walled, amyloid. Basidia cylindric to clavate, thin walled, hyaline, 2-4-spored, sterigmata 2-4 $\mu \mathrm{m}$ long. Hymenial gloeocystidia absent. Pileipellis composed of numerous dermatocystidia, 22-46 $\times 5-8 \mu \mathrm{m}$, cylindrical to versiform, wavy, branched or nodulose, hyaline, inamyloid. Trama of the pileus interwoven, slightly gelatinous, hyphae $2-6 \mu \mathrm{m}$ broad, hyaline, inamyloid; trama of the stipe parallel, 4-12 $\mu \mathrm{m}$ broad, hyaline, dextrinoid, clamp connections absent.

Habitat - growing on dead herbaceous stems and small twigs.

Distribution - Bolivia, Brazil, Brithish Guiana, Ecuador, and Panama (Singer 1974). In Brazil, the species is reported from Blumenau (Santa Catarina), the type locality.

Material examined - Brazil, Santa Catarina, Itapoá, Reserva Biológica Volta Velha, 18 November 2012, Flores, G. 001 (FLOR 49851).

Remarks - Favolaschia rubra fits into section Anechinus, due to its acanthocystidia that are poorly developed or absent, and subsection Rubrinae due to its absent or rare gloeocystidia (Singer 1974). The pileipellis of $F$. rubra is composed by dermatocystidia. The bright red basidiomata distinguishes this species from the others within subsection Rubrinae.

The description here agrees with the original (Bresadola 1896). The type material of this species is from the same region, which was collected in very similar vegetation and a similar climate where our specimens were collected; the distance between the two localities, in the Santa Catarina State, is about $160 \mathrm{~km}$.

Favolaschia selloana Henn., Hedwigia 36(4): 203,1897.

Figs 1D-5

Basidiomata gregarious, usually not confluent; pileus 2-7 mm in diam., semiglobose to fanshaped, sometimes reniform, brownish orange (7C7, 7C6), ligther between the tessellate lines (7A5), becoming yellow brown when dry, glabrous to slightly pruinose, pruina concolorous with the surface; tessellate following the pore dissepiments. Hymenophore poroid, ca. 1-2 pores per $\mathrm{mm}$, tubes grayish orange (6B4); pore irregular, some round near the margin and some alongate near the stipe, pore edges concolorous with the pileus surface. Stipe 2-9 $\mathrm{mm}$ long; grayish orange (6B4), glabrous to slightly pruinose, compressed, laterally attached.

Basidiospores 7-9 $(-10) \times 4-5 \mu \mathrm{m}(\mathrm{Q}=1.93)$, ellipsoid, hyaline, smooth, thin-walled, amyloid. Basidia 28-33 × 6-7 $\mu \mathrm{m}$ clavate, thin walled, hyaline, 2-4-spored, sterigmate 2-3 $\mu \mathrm{m}$ long. Hymenial gloeocystidia 38-48 $\times 6-9 \mu \mathrm{m}$, clavate to fusiform, frequent, with golden yellow oily contents in $\mathrm{H}_{2} \mathrm{O}$ and $3 \% \mathrm{KOH}$, inamyloid. Pileipellis with numerous gloeocystidia $46-86 \times$ 16-19 $\mu \mathrm{m}$, clavate to versiform, with golden yellow oily contents; acanthocystida spiny on the upper two third, 26-46 × 11-13 $\mu \mathrm{m}$; dermatocystidia globose with pedicel, 26-45 $\times 18-22 \mu \mathrm{m}$, hyaline; and ventricose-rostrate 40-47 $\times 11-15 \mu \mathrm{m}$, hyaline. Stipitipellis with elements similar in size and shape from the pileipellis. Trama of the pileus interwoven to sub parallel hyphae, $3-11 \mu \mathrm{m}$ broad, hyaline, inamyloid, with blue small contents in cresyl blue, slightly gelatinized; trama of the stipe parallel, 4-13 $\mu \mathrm{m}$ broad, hyaline, inamyloid, clamp conections present and conspicuous.

Habitat - growing on twigs of angiosperm. 

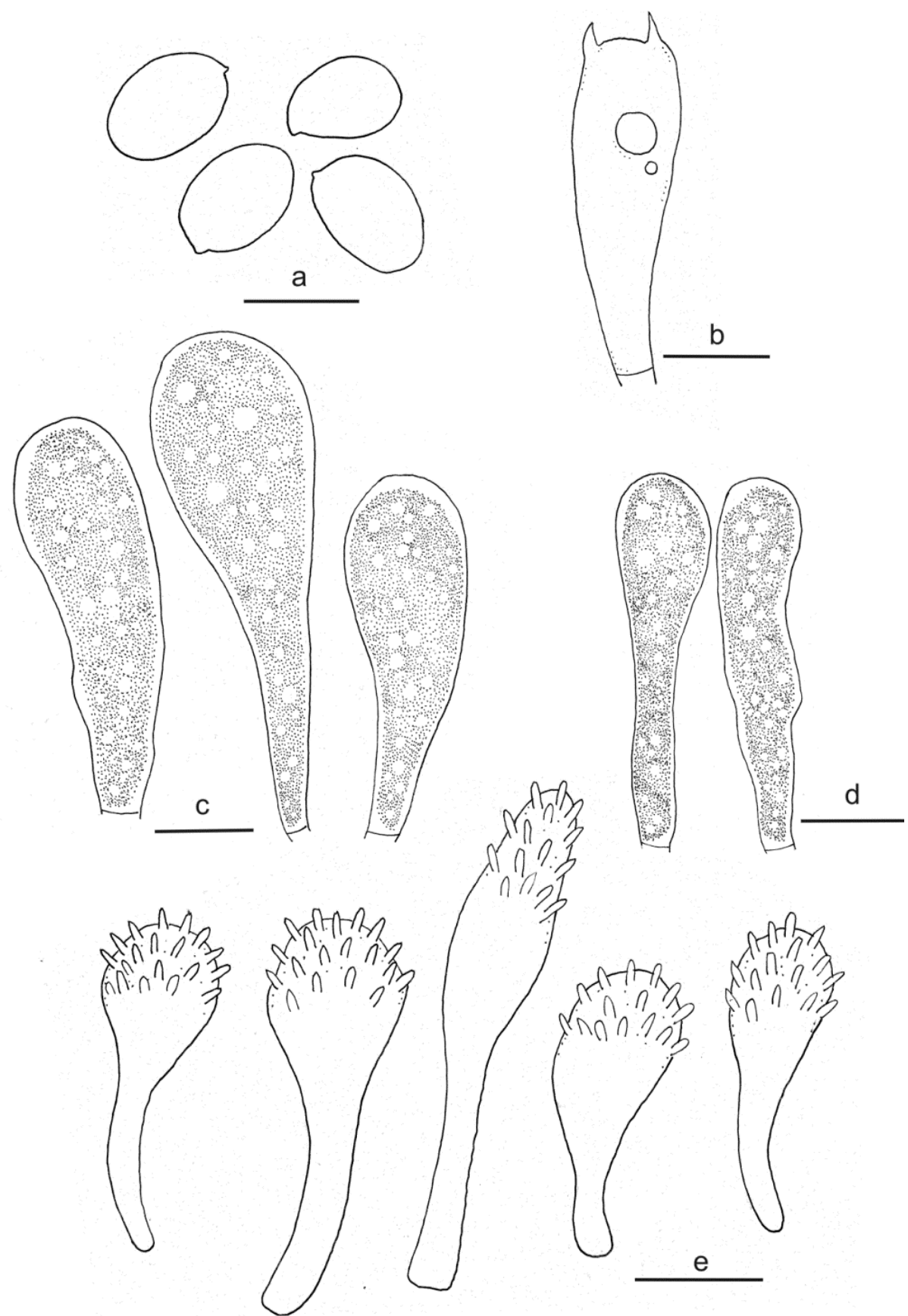

Fig. 2 - Microscopic structures of $F$. cinnabarina: basidiospores, a basidia, b gleocystidia from the pileipellis, $\mathrm{c}$ hymenial gloeocystidia, $\mathrm{d}$ acanthocystida from the pileipellis. $\mathrm{e}-\mathrm{Bar}=10 \mu \mathrm{m}$.

Distribution - Brazil, Bolivia, and Colombia (Singer 1974).

Material examined - Brazil, Espírito Santo, Santa Teresa: Reserva Biológica Augusto Ruschi. 1954'19.60"S, 40³4'8.20"W, 05 Dez 2012, Salvador-Montoya, C.A.. 501 (FLOR 49852).

Remarks - Favolaschia selloana is characterized by its tessellate, orange pileus that is up to $17 \mathrm{~mm}$ in diam. and its orange stipe that is laterally attached and up to $30 \mathrm{~mm}$ long (Hennings 1897). Microscopically it is recognized by the following: elliptical basidiospores, $7-9(-10) \times 4-5$ $\mu \mathrm{m}$; pileipellis with gloecystidia and acanthocystidia; and the presence of hyaline, globose pediculate to ventricose-rostrate dermatocystidia. Favolaschia selloana is placed in section Favolaschia subsection Auriscalpium following Singer (1974). Singer (1945) considered it a subspecies of $F$. thwaitesii (Berk. \& Br.), but later (Singer 1974) kept it as a separate species due to geographical distribution, wider pores, larger stipe, and occasionally larger pileus. 

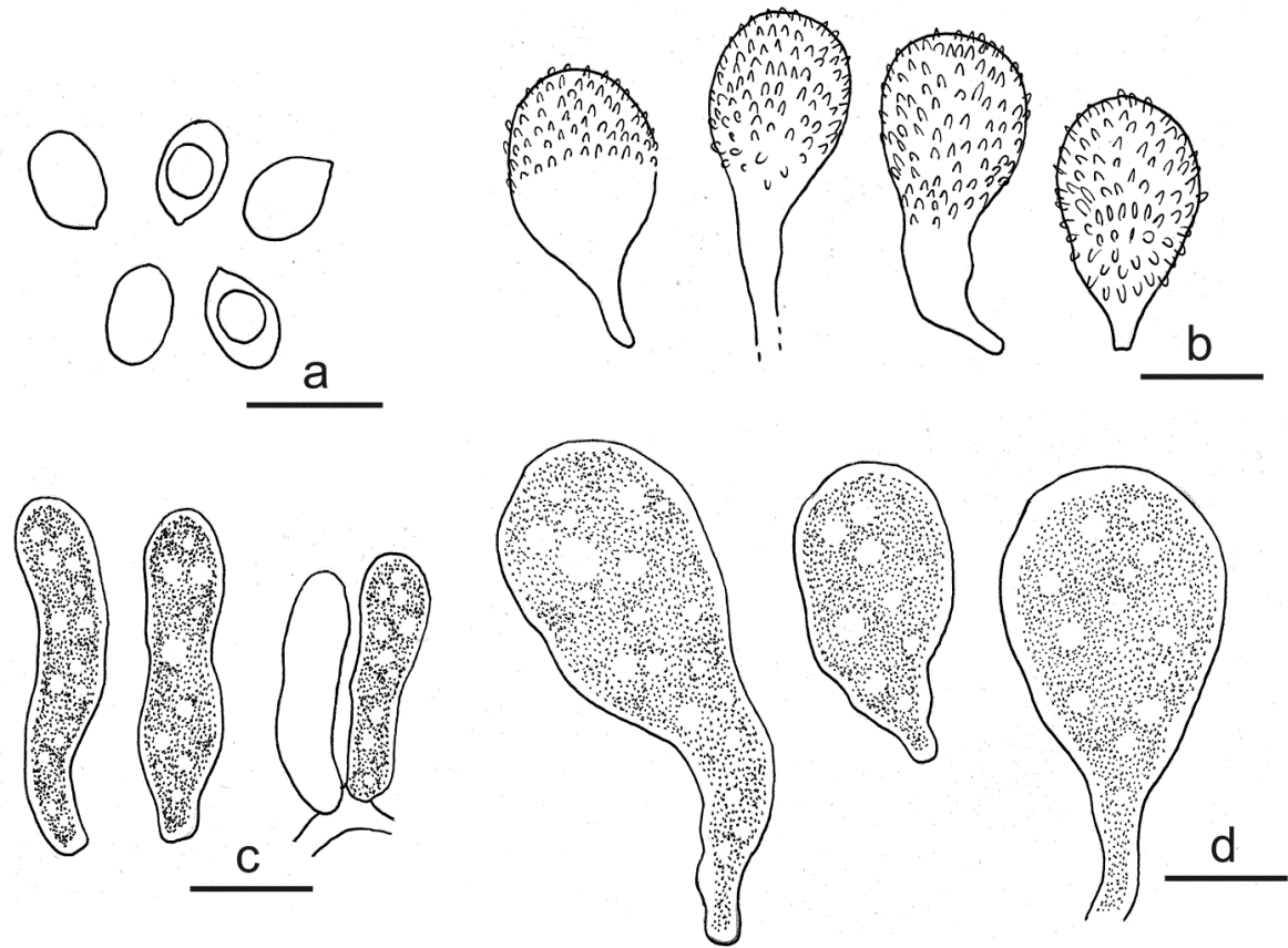

Fig. 3 - Microscopic structures of $F$. dealbata: basidiospores, a acanthocystida from the pileipellis, $\mathrm{b}$ hymenial gloeocystidia, $\mathrm{c}$ gleocystidia from the pileipellis, $\mathrm{d}-\mathrm{Bar}=10 \mu \mathrm{m}$.
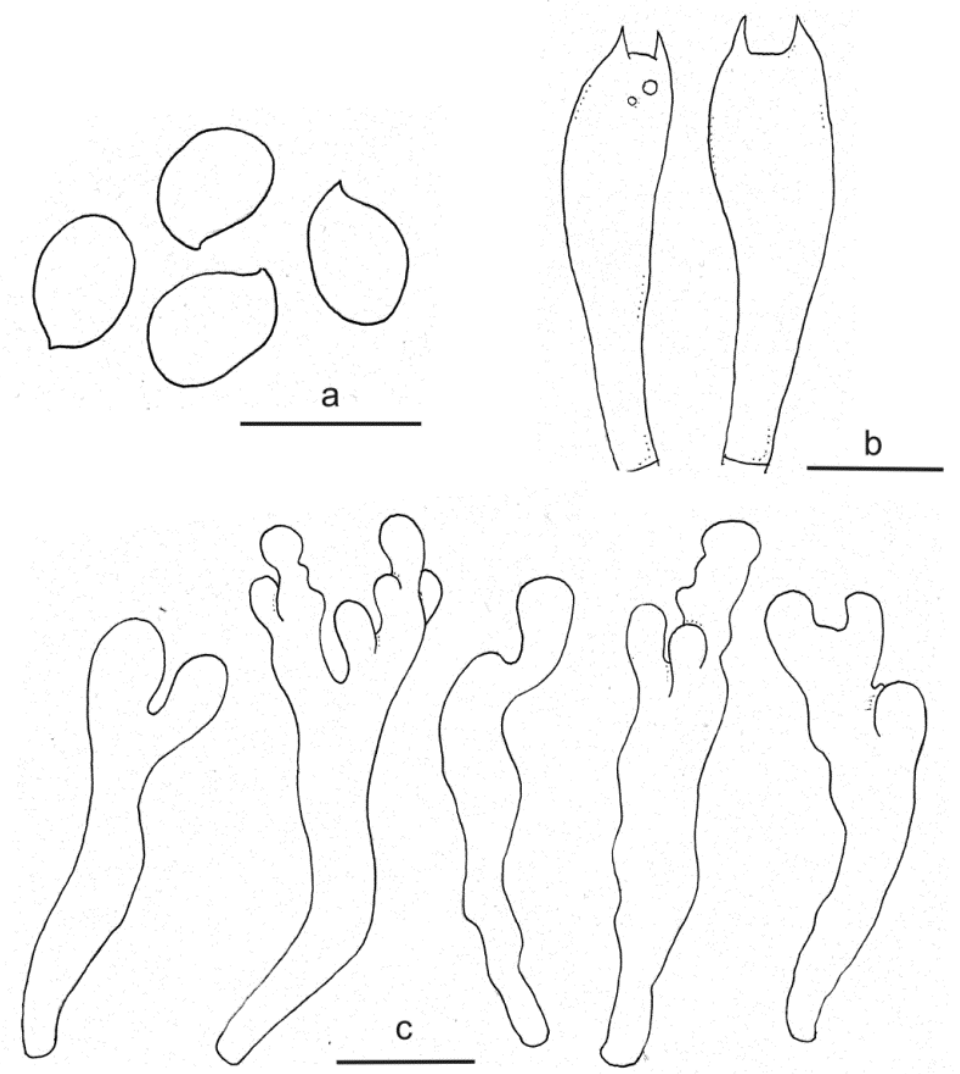

Fig. 4 - Microscopic structures of F. rubra: basidiospores, a basidia, b dermatocystidia, $\mathrm{c}-$ Bar $=$ $10 \mu \mathrm{m}$. 


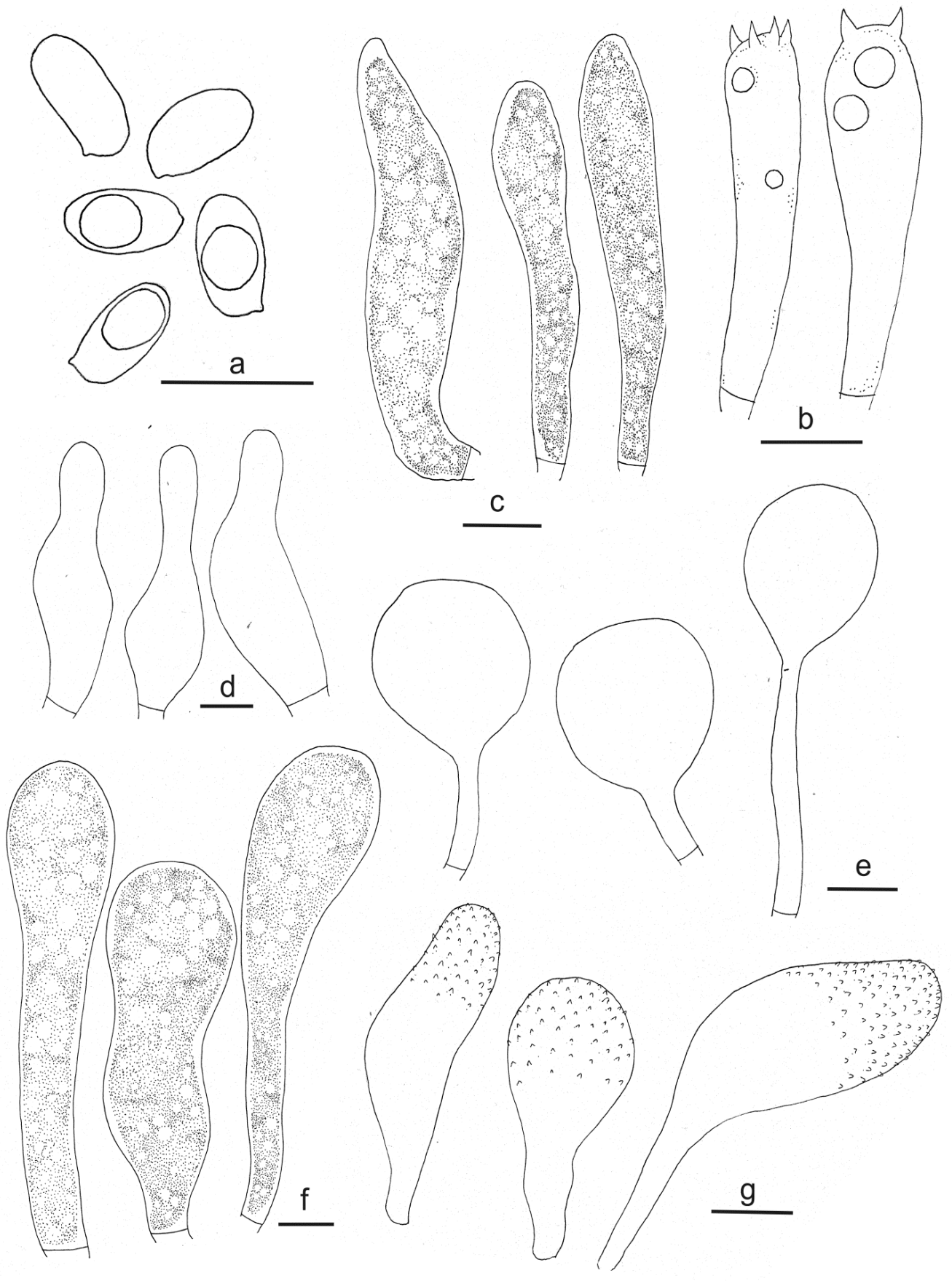

Fig. 5 - Microscopic structures of F. selloana: basidiospores, a basidia, b hymenial gleocystidia, c ventricose dermatocystidia, d globose dermatocystidia with pedicel, e gloeocystidia from the pileipellis, $\mathrm{f}$ acanthocystida from the pileipellis, $\mathrm{g}-\mathrm{Bar}=10 \mu \mathrm{m}$.

\section{Acknowledgements}

Magnago AC and Trierveiler-Pereira L thank the Coordenação de Aperfeiçoamento de Pessoal de Nível Superior (CAPES, Brazil) for the fellowships. We also thank Reserva Biológica Volta Velha and Reserva Biológica Augusto Ruschi for the permits to collect and the support during fieldwork, and Carlos Alberto Salvador Montoya, Diogo Henrique Costa de Rezende, Gustavo Flores and Salomé Urrea Valencia for helping with field collections. The authors acknowledge Hugo B. Mozerle for providing information about one collection site in Santa Catarina, Dr. R. Halling for providing useful literature, and Nathan Smith for reviewing the English. 


\section{References}

Bresadola G. 1896 - Fungi Brasilienses lecti a cl. Dr. Alfredo Möller. Hedwigia 35, 276-302.

Capelari M, Karstedt F, Oliveira JJS. 2013 - Favolaschia in remnants of the Atlantic Forest, Brazil. Mycoscience, doi: 10.1016/j.my c.2013.03.004

Gillen K, Læssøe T, Kirschner R, Piepenbring M. 2012 - Favolaschia species (Agaricales, Basidiomycota) from Ecuador and Panama. Nova Hedwigia 96(1-2), 117-165. doi: 10.1127/0029-5035/2012/0070

Hennings P. 1897 - Beiträge zur Pilzflora Südamerikas II. Hedwigia 36, 190-246.

Kirk PM, Cannon PF, Minter DW, Stalpers JA. 2008 - Dictionary of the fungi, 10th ed. CAB International, Wallingford.

Kornerup A, Wanscher JH. 1978 - Methuen Handbook of Colour, 3rd ed. Eyre Methuen, London.

Magnago AC, Trierveiler-Pereira L, Neves MA. 2013 - Phallales (Agaricomycetes, Fungi) from the tropical Atlantic Forest of Brazil. Journal of Torrey Botanical Society 140(2): 236-244.

Meijer, AAR. 2001 - Mycological work in the Brazilian state of Paraná. Nova Hedwigia 72, 105159.

Meijer AAR. 2006 - Preliminary list of the macromycetes from the Brazilian state of Paraná. Boletin do Museu Botânico Municipal (Curitiba) 68, 1-55.

Meijer AAR. 2008 - Notable Macrofungi from Brazil's Paraná Pine Forest. Colombo, Paraná: Embrapa Floresta.

Parmasto E. 1999 - Favolaschia pegleri, sp. nov. (Hymenomycetes). Kew Bulletin 54, 783-788.

Pegler DN. 1997 - The agarics of São Paulo, Brazil. Royal Botanic Gardens, Kew.

Singer R. 1945 - The Laschia-complex (Basidiomycetes). Lloydia 8(3), 170-230.

Singer R. 1955 - New and interesting species of Basidiomycetes. IV. Mycologia 47(5), 763-777.

Singer R. 1974 - A monograph of Favolaschia. Beihefte Nova Hedwigia 50, 1-108.

Singer R., Fidalgo O. 1965 - Two interesting basidiomycetes from the State of São Paulo. Rickia 2, $11-15$.

Spegazzini C. 1889 - Fungi Puiggariani. Boletín de la Academia de Ciencias de Córdoba 11, 381622.

Thiers B. 2013 - Index Herbariorum: a global directory of public herbaria and associated staff. New York Botanical Garden's Virtual Herbarium. http://sweetgum.nybg.org/ih (accessed 25 June 2013).

Vinha PC. 1988 - Fungos macroscópicos do Estado do Espírito Santo depositados no Herbário Central da Universidade Federal do Espírito Santo, Brasil. Hoehnea 15: 57-64.

Vizzini A, Zotti M, Mello, A. 2009 - Alien fungal species distribution: the study case of Favolaschia calocera. Biological Invasions 11, 417-429. doi: 10.1007/s10530-008-9259-5 